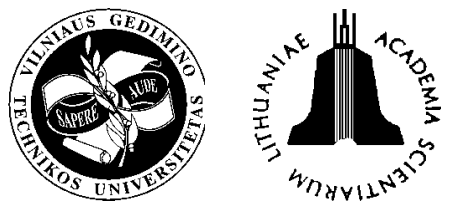

ISSN 1648-4142 TRANSPORT

http:/www.vtu.lt/english/editions

TRANSPORT - 2004, Vol XIX, No 6, 262-268

\title{
DYNAMIC PROCESSES OF THE RETROFITED REAR SUSPENSION OF THE VEHICLE
}

\author{
Marijonas Bogdevičius, Raimundas Junevičius \\ Dept of Transport Technological Eguipment, Vilnius Gediminas Technical University, Plytines g. 27, \\ LT-10105 Vilnius-16, Lithuania.Tel. (+370 5) 27447 82.E-mail: marius@ti.vtu.lt
}

Received 2004-07-18; accepted 2004-10-05

\begin{abstract}
The main aim of the investigation is to design rear suspension and to improve the dynamic characteristics of the vehicle. Three types of rear suspensions that consist of a leaf spring, a hydraulic and a pneumatic damper, an air spring are designed. The dynamic models of the quarter car with these rear suspensions are presented. Random disturbance of particular road surface is played back by using a spectral density and Monte Carlo method. Natural frequencies of rear suspension are presented. The dependence of standard deviations of the first, the second and the third derivates of particular random displacements on the vehicle speed is obtained. Dynamic characteristics of three rear suspensions are compared and the best rear suspension is determined.
\end{abstract}

Keywords: vehicle, rear suspension, dynamics, numerical methods.

\section{Introduction}

The structure of rear suspension influences on the characteristics of the vehicle, i.e not only on comfortable and safe driving, but also on the payload volume in the passenger and baggage sections. Since the space for the elements of suspension is scarce, their layout shall be as compact as possible, but they shall be functional. Pivot elements of the wheel shall turn the wheel in the direction perpendicular to the direction of the vehicle movement as little as possible (not to increase the rutting). Displacing vertically a wheel shall change the inclination angle to the road surface as little as possible. The durability of joints and wear of tyres are influenced by the positioning of all elements of the suspension. Smooth operation of the suspension elements governs the kinematical and dynamic characteristics of the vehicle suspension.

Vehicles are upgrading, their driving speed and acceleration increase, therefore, a contact of a wheel with the road surface can be lost, adhesion coefficient reduced and the braking distance increased. High speed and the acceleration of suspension parts can be the cause of a contact with the vehicle body.

In the case of improving passengers comfort in a cabin, safety characteristics are decreased, and vice versa, when the safety characteristics are improved, the drivers' and passengers' comfort is decreased.

Comfort and safety arrangement is one of the main problems faced by passenger bus manufacturers and retrofitters. All over the world minibuses are manufactured by retrofitters or bodybuilders. Retrofitting is usually carried out on the base of a van, therefore, to improve the comfort of passengers the suspension of the bus shall be improved.

The most popular retrofitting method is setting of an additional elastic element, for example, an air spring into the bus suspension.

\section{Modification of the bus suspension}

The investigation of minibus suspension dynamics is presented in this paper when the van suspension is retrofitted into minibus suspension. The aims of the research are: 1) to compare the dynamics of cargo van leaf spring suspension and improved suspension of a minibus, 2) to identify the influence of additionally added elements on the dynamic characteristics of the suspension as well as to identify priority trends of suspension improving.

Leaf spring suspensions are modified in two ways: 1) an additional elastic element is added into the suspension system; 2) the structure of suspension is modified by modifying the structure of the spring and adding an additional elastic element. These structural solutions are not complicated. However, to implement the solutions properly, in the first case additional brackets shall be mounted on the vehicle axis and the body where the air spring is attached, also additional equipment shall be mounted to keep pressure in an air spring. In the second case a completely new leaf 
spring shall be mounted; the body of the bus shall be reinforced since the spring fastening points are changed; possible displacement of the axis shall be limited according to the body of a minibus; additional equipment shall be mounted to keep pressure in an air spring.

There are three bus suspensions under investigation. Dynamic characteristics of the vehicle are verified by driving on the most common road pavements: asphalt concrete, concrete, cobble-stone and gravel.

Vehicle suspension reduces the impact of road pavement roughness on the body. Therefore, suspension wear, tear and dumping characteristics shall ensure safe and comfortable conditions of carrying passengers and cargo. The analysis of the process smoothness is usually carried out taking the impact of vibrations on a human being into consideration (Fig 1). Norms of the impact of vibrations on a human do not have essential differences in various countries, and are co-ordinated during harmonized disturbance (Fig 1) [1-3].

Road surface grades are described by the function of spectral density (Fig 2).

$$
S_{u}(\omega)=\frac{2 \cdot \sigma^{2}\left(\alpha^{2}+\beta^{2}+\omega^{2}\right)}{\left(\alpha^{2}+\beta^{2}\right)+2 \cdot\left(\alpha^{2}-\beta^{2}\right) \omega^{2}+\omega^{4}} ;
$$

here $\sigma$-standard deviation; $\alpha=\alpha_{1} v ; \beta=\beta_{1} v ; v-$ movement speed.

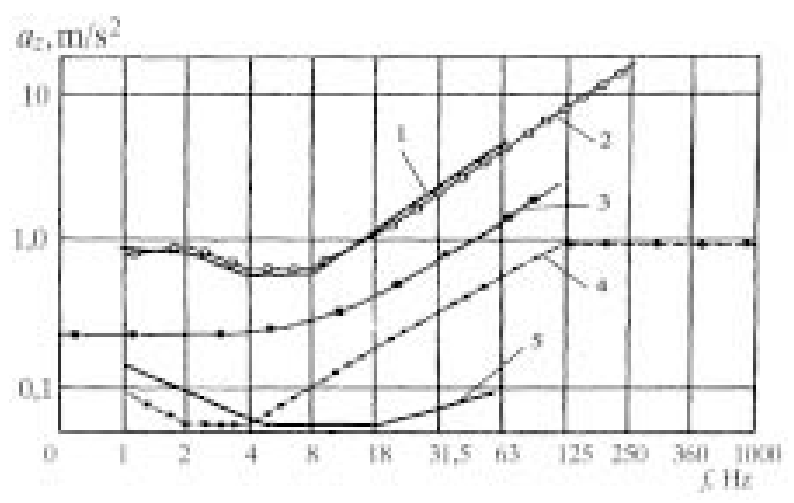

Fig 1. Standard deviations of acceleration determined in various countries are as follows: 1 - Great Britain, France;

2 - Russia; 3 - Germany; 4 - Finland; 5 - USA

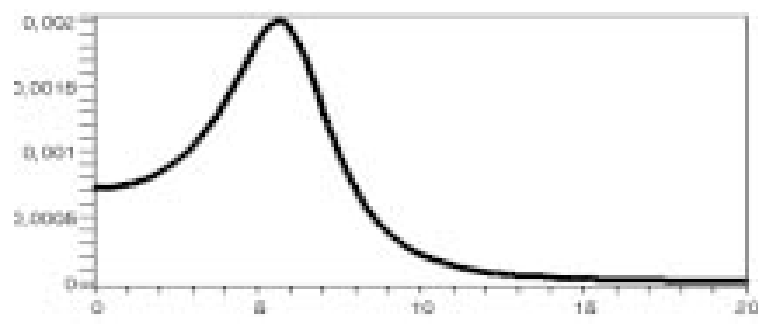

Fig 2. Spectral density
Standard deviations of various types of road pavement are as follows: asphalt concrete $-\sigma=0,010$ $\mathrm{m}$; concrete pavement $-\sigma=0,0065 \mathrm{~m}$; cobble-stone road $\sigma=0,0242 \mathrm{~m}$; earth road - $\sigma=0,0242 \mathrm{~m}$ [4-5].

Three rear spring suspensions of the bus are under investigation. The first is a typical suspension of a basic vehicle on the basis of which modifications were carried out. Suspensions of this type are used in the vehicles of Mercedes Benz Sprinter, VW LT, Iveco Daily, the gross mass of which does not exceed 3,500$4,200 \mathrm{~kg}$. The structure of the suspension is not complicated. It consists of the following: a half of the axle mass, mass of the wheel and a hub, a spring, and a damper. The dynamic models of these suspensions are presented in Figs 3 a and 4 a).

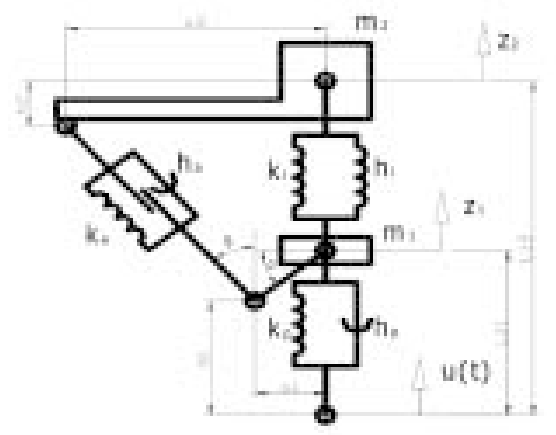

a)

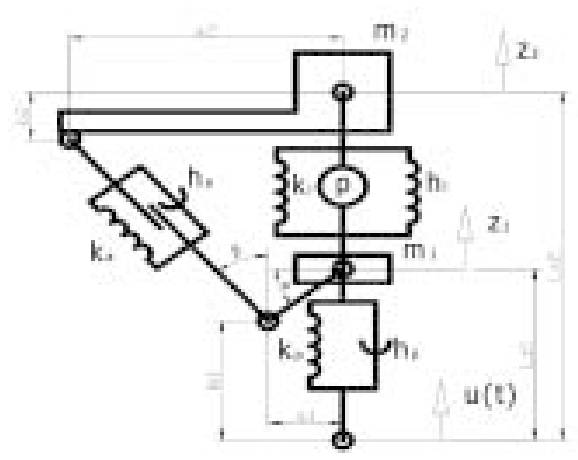

b)

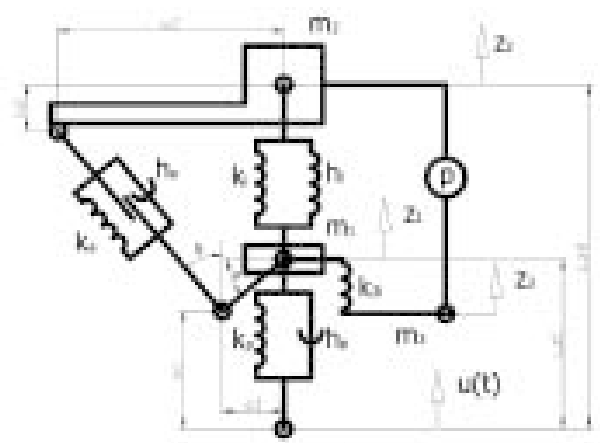

c)

Fig 3. Dynamic models of the vehicle rear spring suspension: a) rear spring suspension of the basic vehicle; b) upgraded rear spring suspension; c) model of rear modified spring suspension 
The leaf spring is fastened to the body by a cylindrical joint at one end. While the vehicle axis moves vertically, this end may revolve only on its axis.

The other end of the spring is attached to the body through an additional cylindrical joint and a rod. The latter structural solution enables to move the end of the spring longitudinally in cases when the spring is deformed (straightened). The vehicle axis is stationary to the spring; therefore, when the spring is deformed, longitudinal wheel displacement occurs. The position of each element is limited by the other components of suspension; therefore, the elements of suspension as well as the whole set of elements may move only in certain space.

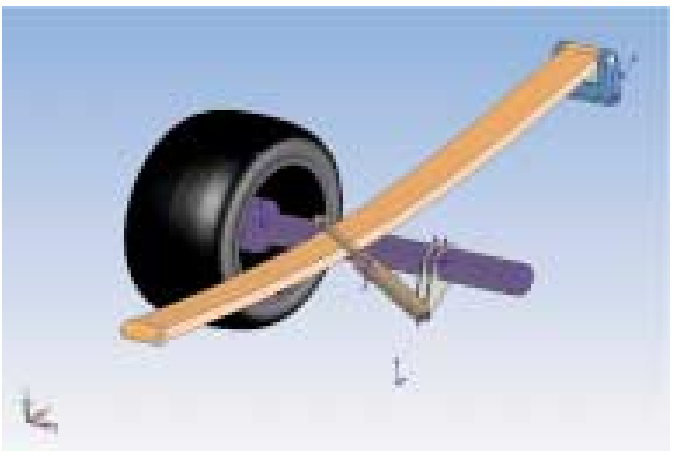

a)

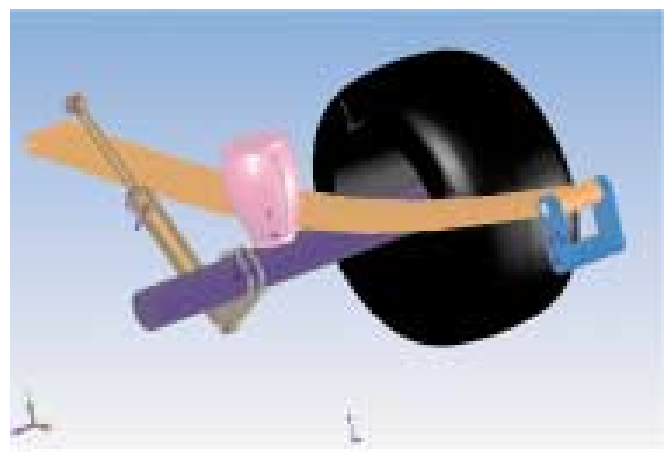

b)

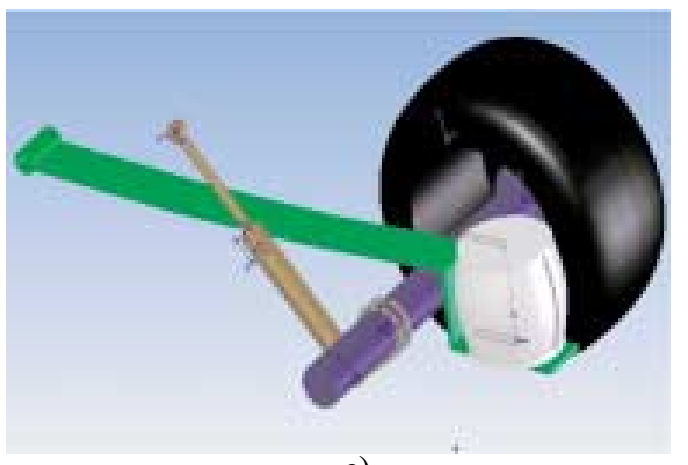

c)

Fig 4. 3 D modes of the vehicle rear leaf spring suspensions; a) rear leaf spring suspension of the basic vehicle; b) upgraded rear leaf spring suspension; c) model of rear modified leaf spring suspension
The second structure of the rear spring suspension is an upgraded structure of the basic spring suspension (Figs $3 b, 4 b$ ). It is comprised of a half of the axle mass, wheel and hub mass, a leaf spring, a damper and an additionally introduced elastic element: an air spring, the bottom of which is attached to the rear axis of the bus and the top is fixed to the body of the bus. The position of each element is limited by the other components of suspension; therefore, the elements of suspension as well as the whole set of elements may move only in certain space.

The third structure of the rear spring suspension is modified compared to the traditional suspension of the van. The suspension of the bus quarter consists of a half of the axle mass, wheel and hub mass, a leaf spring, an air spring, and a damper (Figs $3 \mathrm{c}, 4 \mathrm{c}$ ).

\section{The equation system of modified spring suspen- sion movement}

The equation system of modified spring suspension dynamic model (Fig $3 \mathrm{c}$ ) movement is as follows:

$$
\begin{aligned}
& m_{1} \ddot{z}_{1}=-m_{1} g+F_{1 z}\left(z_{1}, z_{2}, \dot{z}_{1}, \dot{z}_{2}\right)- \\
& k_{p}\left(z_{1}-u(t)\right)-h_{p}\left(\dot{z}_{1}-\dot{u}(t)\right) ; \\
& m_{2} \ddot{z}_{2}=-m_{2} g+F_{2 z}\left(z_{1}, z_{2}, \dot{z}_{1}, \dot{z}_{2}\right)- \\
& k_{l}\left(z_{2}-z_{1}\right)-h_{l}\left(\dot{z}_{2}-\dot{z}_{1}\right)+S_{0 p} ; \\
& m_{3} \ddot{z}_{3}=-m_{3} g-k_{3 l}\left(z_{2}-z_{1}\right)-S_{0} p ; \\
& \dot{p}=\frac{-\gamma S_{0} p\left(\dot{z}_{2}-\dot{z}_{3}\right)}{V_{0}+S_{0}\left(z_{2}-z_{3}\right)} ; \\
& F_{1 z}=\frac{f}{L_{21}}\left(c_{21}+z_{2}-z_{1}\right) ; \\
& F_{1 z}=-\frac{f}{L_{21}}\left(c_{21}+z_{2}-z_{1}\right) ; \\
& c_{21}=L_{z 2}-b_{2}-L_{z 1}+e \sin (\alpha) ; \\
& f=k_{a} L_{21}+h_{a} \dot{L}_{21}+f_{0} \operatorname{sign}\left(\dot{L}_{21}\right) ; \\
& L_{21}=\frac{1}{L_{21}}\left(c_{21}+z_{2}-z_{1}\right)\left(\dot{z}_{2}-\dot{z}_{1}\right) ; \\
& c_{21}+z_{2}-z_{1}
\end{aligned} ;
$$

here $h_{p}, h_{l}, h_{a}$ - damping coefficients of the tyre, spring and hydraulic amortizator, respectively; 
$k_{p}, k_{l}, k_{3 l} k_{a}-$ stiffness coefficients of the tyre, spring, the end of the spring and hydraulic amortizator, respectively; $S_{0}-$ the area of the air cushion; $u(t)$-vertical coordinate of the road surface; $\gamma$ - adiabatic indicator; $V_{0}$ - initial volume of the air cushion; $m_{1}-$ half of the axle mass; $m_{2}$ - mass of the bus body quarter; $m_{3}$ - mass of the spring part.

When integrating the equation system of the modified spring suspension movement, road surface roughness height corresponding to the spectral density (1) is generated at every moment of time $u(t)$.

Equation system of the suspension can be described in a vector shape:

$$
\{\dot{x}\}=\{F(x, \dot{x}, u, t)\} .
$$

Initial conditions of this function are: $\{x(t=0)\}=0 ; \quad u(t)=0$; Suspension dynamic model takes a new position from the load of body mass and the equation (11) has a solution $\left\{x_{0}\right\}$, then the system of equations (11) is linearized about point $\left\{x_{0}\right\}$. The new equation is:

$$
\{\dot{x}\}=[A]\left\{x_{p}\right\}+\left[B_{0}\right]\{u\}+\left[B_{1}\right]\{\dot{u}\} .
$$

The equation (12) can be written:

$$
\{X(\omega)\}=[H(i \omega))\{U(\omega)\},
$$

where $[H(i \omega)]$ - transfer matrix,

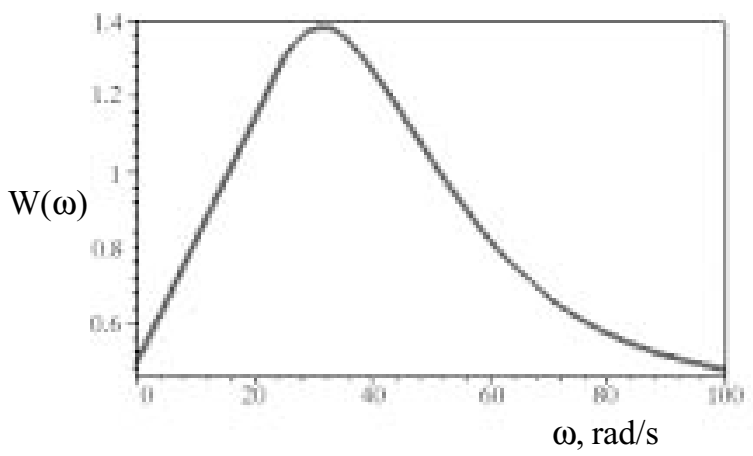

Fig 5. Human response on frequency

$$
[H(i \omega)]=(i \omega[E]-[A])^{-1}\left(B_{0}+i \omega\left[B_{1}\right]\right) ;
$$

where $\mathrm{A}, \mathrm{B}, \mathrm{B}_{0}, \mathrm{E}-$ matrix, $\omega$ - frequency. Average square deviation of acceleration of the minibus typical masses are described by the equation:

$$
\sigma_{x k}^{2}=\frac{1}{2 \pi} \int_{-\infty}^{\infty} S_{\mu}(\omega) W(\omega) \sum_{j=1}^{n}\left|H_{k j}\right|^{2} d \omega ;
$$

$S_{u}(\omega)$ - spectral density of knematic disturbance $\mathrm{u}(\mathrm{t})$, $W(\omega)$ - Human response on frequency (Fig 5).

\section{Dynamic characteristics of spring suspension}

The parameters of the bus spring suspensions under investigation are as follows:

$m_{1}=50 \mathrm{~kg}, m_{2}=900 \mathrm{~kg}, m_{3}=1,5 \mathrm{~kg}, h_{p}=2500$ $\mathrm{Ns} / \mathrm{m}, \quad h_{1}=11200 \mathrm{Ns} / \mathrm{m}, \quad k_{p}=1127000 \mathrm{~N} / \mathrm{m}$, $k_{1}=1000 \mathrm{~N} / \mathrm{m}, k_{31}=250000 \mathrm{~N} / \mathrm{m}, b_{1}=0,30 \mathrm{~m}$, $b_{2}=0,50 \mathrm{~m}, a_{1}=0,20 \mathrm{~m}, \alpha=\frac{\pi}{4}, f_{0}=30 \mathrm{~N}$, $V_{0}=0,003 \mathrm{~m}^{3}, \gamma=1,4, S_{0}=0,0201 \mathrm{~m}^{2}$.

Natural frequencies of vibrations of the spring suspension systems under investigation are presented in Table 1. Concrete values of suspension body accelerations depending on the stimulation amplitude are presented in Table 2 and Fig 6.

The impact of air springs volume on the dynamic process of the bus suspension has been investigated. Air springs of three different volumes were selected: $0,3 \mathrm{~m}^{3}, 0,03 \mathrm{~m}^{3}$ and $0,003 \mathrm{~m}^{3}$. It was identified that when the volume of air springs reduces, natural frequency of suspension and pressure variation amplitude in the air spring increase. Concrete pressure amplitudes and values of natural frequency are presented in Table 3. The Highest values of bus body acceleration are presented in Table 4. Average square deviation of a minibus body of all three schemes when the driving speed is $v=5 \ldots 70 \mathrm{~m} / \mathrm{s}$ is presented

Table 1. The highest amplitude frequencies of suspension characteristic points natural vibrations

\begin{tabular}{|c|c|c|c|}
\hline $\begin{array}{c}\text { Number } \\
\text { degree of } \\
\text { freedom }\end{array}$ & $\begin{array}{c}\text { Suspension No 1 } \\
\text { Natural frequencies of } \\
\text { vibrations, Hz }\end{array}$ & $\begin{array}{c}\text { Suspension No 2 natural } \\
\text { frequencies of vibrations, Hz }\end{array}$ & $\begin{array}{c}\text { Suspension No 3 } \\
\text { natural frequencies of } \\
\text { vibrations, Hz }\end{array}$ \\
\hline 1 & 23,8 & 23.6 & 135,8 \\
\hline 2 & 23,8 & 23.6 & 135,8 \\
\hline 3 & 2,39 & 0.00 & 20,5 \\
\hline 4 & 2,39 & 2.70 & 20,5 \\
\hline 5 & - & 2.70 & 2,03 \\
\hline 6 & - & - & 0,03 \\
\hline 7 & - & - & 00 \\
\hline
\end{tabular}


Table 2. The highest values of the bus body acceleration when the road surface disturbance amplitude varies

\begin{tabular}{|c|c|c|c|}
\hline Initial disturbance amplitude, $\mathrm{m}$ & Frequency, $\mathrm{Hz}$ & Acceleration, $\mathrm{m} / \mathrm{s}^{2}$ & Scheme No \\
\hline 0.02 & 2.38 & 0,129 & 1 \\
\hline 0.01 & 2.38 & 0,0647 & 1 \\
\hline 0.005 & 2.38 & 0,0324 & 1 \\
\hline 0.001 & 2.38 & 0,0065 & 2 \\
\hline 0.02 & 2.69 & 0,1309 & 2 \\
\hline 0.01 & 2.69 & 0,0655 & 2 \\
\hline 0.005 & 2.69 & 0,0328 & 3 \\
\hline 0.001 & 2.69 & 0,00655 & 3 \\
\hline 0.02 & 2.00 & 0,0794 & 3 \\
\hline 0.01 & 2.00 & 0,0397 & 3 \\
\hline
\end{tabular}

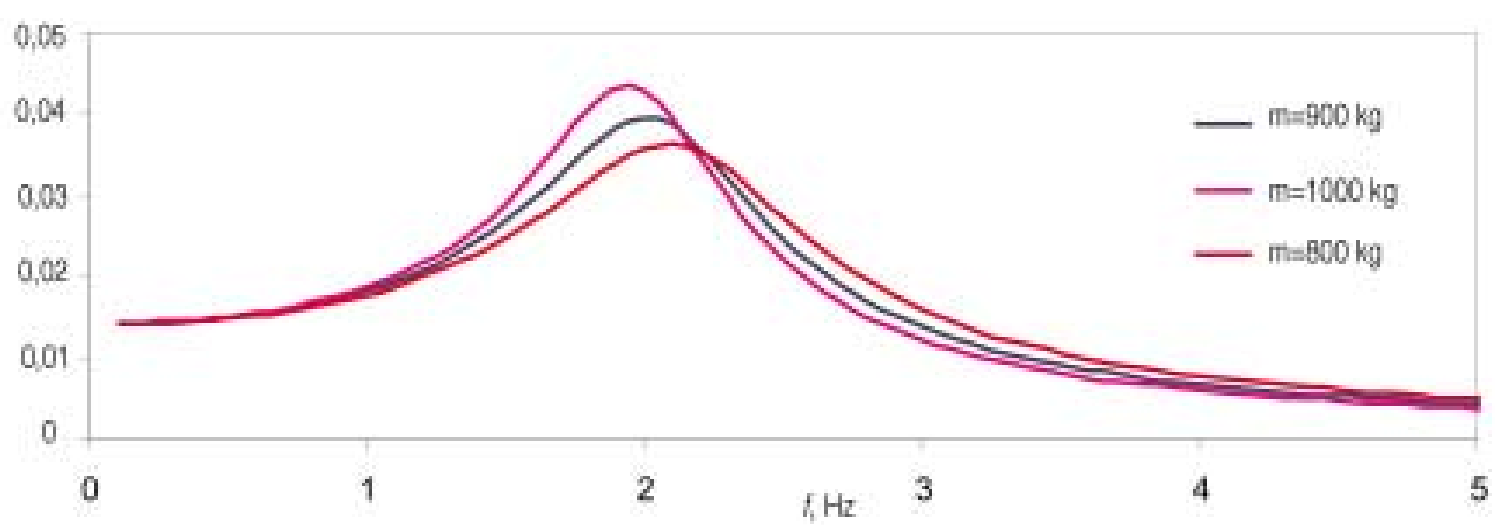

Fig 6. Amplitude frequency characteristics of scheme N 3. Dependence of body acceleration on the frequency when the initial disturbance amplitudes are different

Table 3. Values of the highest amplitudes of the bus air spring pressure

\begin{tabular}{|c|c|c|c|}
\hline $\begin{array}{c}\text { Volume of air } \\
\text { spring, } \mathrm{m}^{3}\end{array}$ & $\begin{array}{c}\text { Frequency, } \\
\mathrm{Hz}\end{array}$ & $\begin{array}{c}\text { Pressure, } \\
\mathrm{kPa}\end{array}$ & $\begin{array}{c}\text { Scheme } \\
\text { No }\end{array}$ \\
\hline 0,003 & 2,72 & 12,568 & 2 \\
\hline 0,03 & 2,45 & 1,258 & 2 \\
\hline 0,3 & 2,42 & 0,126 & 2 \\
\hline 0,003 & 2,10 & 9,379 & 3 \\
\hline 0,03 & 1,70 & 1,059 & 3 \\
\hline 0,3 & 1,60 & 0,109 & 3 \\
\hline
\end{tabular}

Table 4. The highest values of the bus body acceleration when the volume of the air spring changes

\begin{tabular}{|c|c|c|c|}
\hline $\begin{array}{c}\text { Volume of } \\
\text { air spring, } \\
\mathrm{m}^{3}\end{array}$ & $\begin{array}{c}\text { Frequency, } \\
\mathrm{Hz}\end{array}$ & $\begin{array}{c}\text { Vertical } \\
\text { acceleration } \\
\mathrm{m} / \mathrm{s}^{2}\end{array}$ & $\begin{array}{c}\text { Scheme } \\
\text { No }\end{array}$ \\
\hline 0,003 & 2,71 & 0,0653 & 2 \\
\hline 0,03 & 2,41 & 0,0539 & 2 \\
\hline 0,3 & 2,38 & 0,0526 & 2 \\
\hline 0,003 & 2,00 & 0,0396 & 3 \\
\hline 0,03 & 1,60 & 0,0294 & 3 \\
\hline 0,3 & 1,50 & 0,0281 & 3 \\
\hline
\end{tabular}

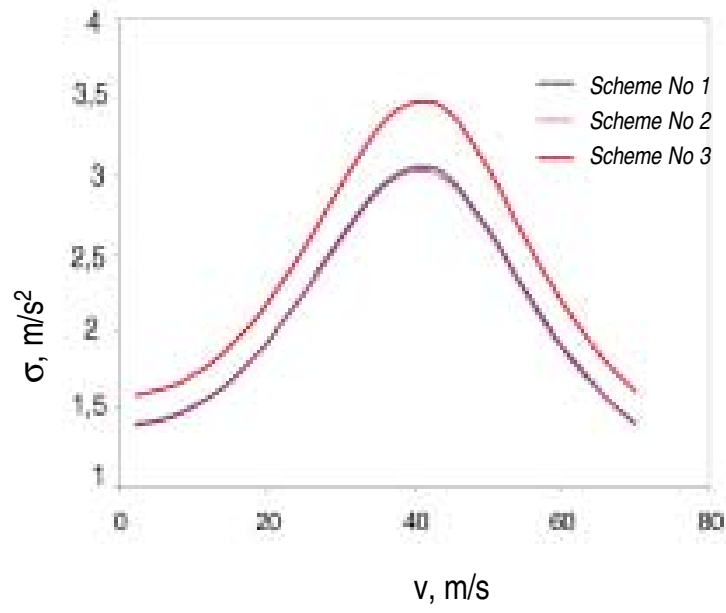

Fig 7. Average square deviation of a minibus body on driving speed

in Fig 7. Bus body acceleration dependence on time (Fig 8-10) and pressure in air spring dependence on time are presented in Figs 11 and 12. 


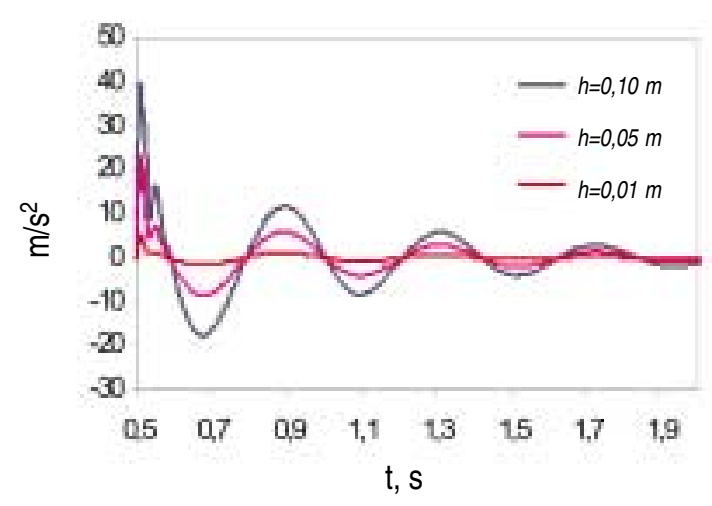

Fig 8. Minibus body acceleration (scheme 1) dependence on time in case of driving by" foot step" disturbance

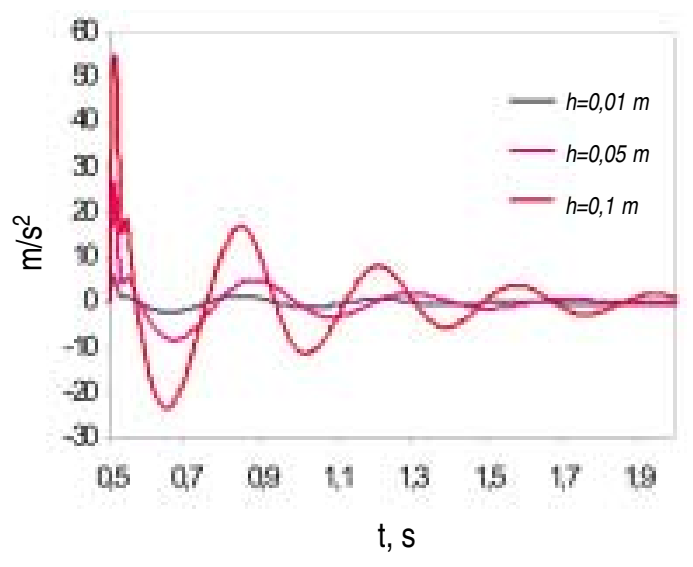

Fig 9. Minibus body acceleration (scheme 2) dependence on time in the case of driving by "foot step" disturbance

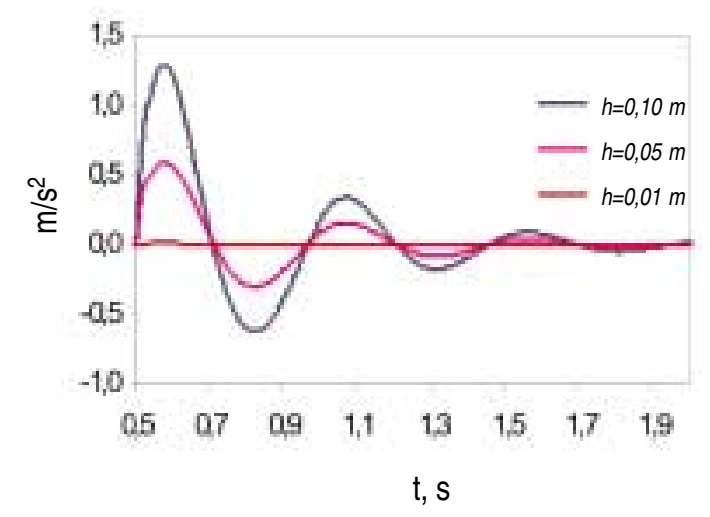

Fig 10. Minibus body acceleration (scheme 3) dependence on time in the case of driving by "foot step" disturbance

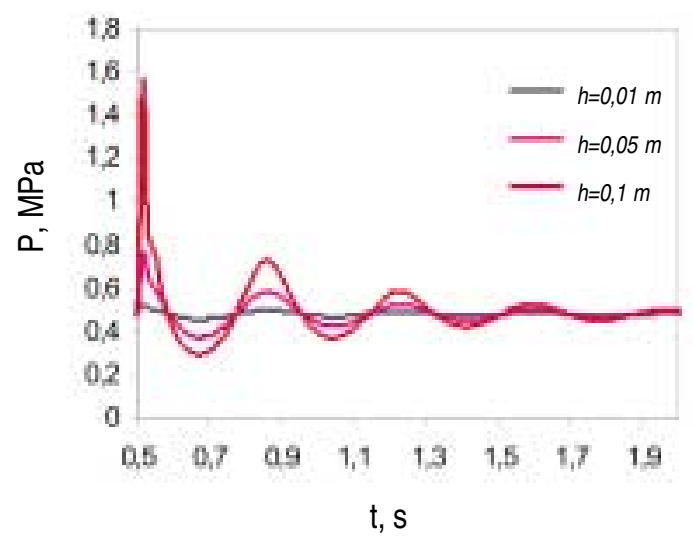

Fig 11. Minibus air spring presure (scheme 2) dependence on time in the case of driving by "foot step" disturbance

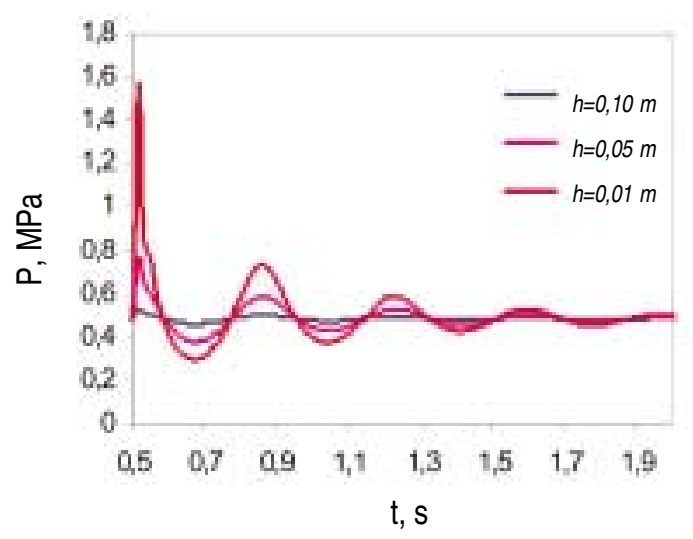

Fig 12. Minibus air spring presure (scheme 3) dependence on time in the case of driving by " foot step" disturbance

\section{Conclusions}

1. Comparing three bus suspensions, it was noticed that natural frequencies of all three suspensions are from $2 \mathrm{~Hz}$ to $3 \mathrm{~Hz}$. The acceleration amplitude of the third suspension body and natural frequencies are lower than those of the first and the second suspensions.

2. When the mass of the body increases, the body acceleration amplitude increases from $0,0362 \mathrm{~m} / \mathrm{s}^{2}$ to $0,0702 \mathrm{~m} / \mathrm{s}^{2}$, and the frequency of fluctuations decreases from $2,84 \mathrm{~Hz}$ to $1,90 \mathrm{~Hz}$.

3 . When the air spring volume increases from $0,003 \mathrm{~m}^{3}$ to $0,3 \mathrm{~m}^{3}$, vertical accelerations of the body decrease from $0,0653 \mathrm{~m} / \mathrm{s}^{2}$ to $0,0281 \mathrm{~m} / \mathrm{s}^{2}$.

4. Damping of the third suspension vertical accelerations in the case of driving over the obstacle is the best. In the case of overcoming $0,1 \mathrm{~m}$ high rectangular obstacle, the acceleration of the third suspension is $1,29 \mathrm{~m} / \mathrm{s}^{2}$. The pressure of the third suspension 
air spring in the case of overcaming the obstacle is lower than the second one (1,579 MPa scheme No 2 and 1,425 MPa scheme No 3).

5. In the case of using suspension with an air spring it is recommended to use air springs of larger volume. The structure of the third suspension is the most comfortable and the structure of the second suspension is the most rigid. Such characteristics of the suspension are determined by the structural differences.

\section{Referenses}

1. Aladjev, V:; Bogdevicius, M. Maple 6: Solution of Mathematical, Statistical, Engineering and Physical Problems. Moscow: BINOM, 2001. 850 p., CD-ROM, ISBN 593308-085-X.

2. Aladjev, V.; Bogdevičius, M.; Vaganov, V. Systems of Computer Algebra: New Software Toolbox for Maple. Tallinn: International Academy of Noosphere, 2004. 462 p., ISBN 9985-9277-8-8.

3. Prentkovskis, O. Interaction Between the Vehicle and Obstacles: Summary of Doctoral Dissertation: Technological Sciences, Transport Engineering (03T). Vilnius: Technika, 2000. $56 \mathrm{p}$.

4. Bogdevičius, M.; Prentkovskis, O. Simulation of Transport Vehicle Interaction with Road Fence. Transport Engineering (Transportas), Vol 6(14). Vilnius: Technika, 1999, p. 289-296 (in Lithuanian).

5. Bogdevičius, M.; Prentkovskis, O. Mathematic Simulation of Transport Vehicle Interaction with Obstacle. In: Proceedings of International Conference "Safety on Road: SORIC'98", 26-28 October, 1998. Bahrain Conference Center: University of Bahrain Press, 1998, p. $7-8$. 